\title{
Prefácios de livros didáticos e o imaginário da leitura: do dado marginal à legitimação de um lugar
}

da escrita

\author{
School books prefaces and the imaginary on \\ reading: from the marginal datum to the legitimacy \\ of a position for writing
}

\section{Préfaces de livres didatiques et l'imaginaire du lecture: des indices périphériques à légitimation d'une place pour l'écriture}

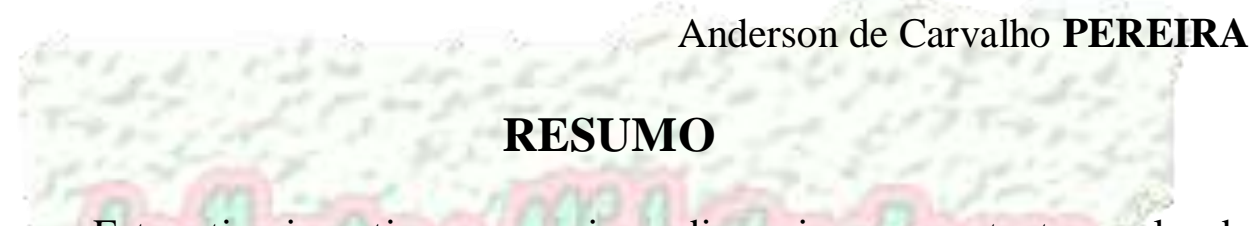

Este artigo investiga o mecanismo discursivo que sustenta o valor de verdade agregado às definições e às proposições de uso da escrita, tal como aparecem em prefácios de livros didáticos de português brasileiro utilizados na alfabetização. Foram analisadas sequências discursivas que sinalizam mecanismos ideológicos de sustentação do sentido de natureza, transparência e instrumentalização da língua, que reforçam o sujeite cognitivo e apagam possibilidades de marcação de posições de intếrprete por parte do sujeito do discurso.

Palavras-chave: letramento, livro didático, discurso, escrita.

\begin{abstract}
This paper aims at investigating the discourse strategies that offer the status of truth to definitions and propositions related to the usages of writing as presented in Brazilian school books for literacy learning in Portuguese. Discursive sequences were analyzed, disclosing ideological processes that conferred the perception of the language as something natural, transparent and instrumental, and reinforced the ideal of a cognitive subject, suppressing the possibilities of interpretation by the subject of the discourse.
\end{abstract}

Index terms: literacy, school book, discourse, writing. 


\section{RÉSUMÉ}

Cet article examine le mécanisme discursif qui soutient la valeur de la vérité ajouté aux definitions et aux propositions de l'utilisation de l'écriture démontrés dans les préfaces des livres didatiques du portugais brésilien utilisés dans l'alfabétisation. Des séquences discursives ont été analysés parce qu'elles signalisent les mécanismes idéologiques du sens de la nature, de la transparence et l'instrumentalisation de la langue, qui renforcent le sujet cognitive et effacent des possibilités de démarcations des positions d'interprète par rapport au sujet du discours.

Mots-clés: «letramento», livre didactique, discours, écriture.

\section{Introdução}

É velha conhecida a legitimação conferida à posição social de quem detém os recursos da escrita; recentemente, este poderio decorre da sua associação à cartilha escolar.

No Egito antigo, os escribas detinham marcadamente o controle da escrita; na Grécia, por sua vez, havia uma menor relevância da escrita administrativa no cotidiano, o que valorizava as práticas orais; isto pode ser constatado, por exemplo, pelo debate político na via pública, principalmenté com o fortalecimento do modelo de democracia proposto por Péricles (THOMAS, 2005).

A desconfiança que o texto escrito suscitava na Grécia Antiga vinha da estreita ligação ou mesmo da personificação comum entre aqueles que escreviam os manuais de ensino da escrita e os sofistas. Estes mestres da arte retórica propagam uma desconfiança da escrita, cuja proporção é vista inclusive no Fédon de Platão (THOMAS, 2005).

Pretendemos neste artigo, dar outra forma a esta associação, mostrando que, de outro lugar, podemos denunciar que a cartilha assegura principalmente sentidos dominantes, que, muitas vezes, impedem o sujeito de assumir posições discursivas de resistência, lugares de intérprete, frente aos padrões ali estabelecidos como usuais para um suposto desenvolvimento da aquisição da escrita. 
De maneira mais circunscrita, o objetivo deste artigo é analisar formas discursivas da escrita veiculadas em prefácios de livros didáticos. Isto se justifica pela maciça presença deste recurso da escrita nos círculos escolares brasileiros e em seu mercado editorial, bem como, ironicamente pela raridade das publicações em torno desta questão, como bem apontou Coracini (1999).

Ao considerar a escrita como veiculadora de diferentes constituintes históricos, este artigo investiga a dimensão pública e pedagógica assumida pela escrita veiculada em livros didáticos. Mais especificamente, nossa tentativa é de mostrar como os enunciados circulam em prefácios de livros didáticos perfazem zonas de sentido dominantes acerca da escrita comolum objeto de conhecimento.

\section{I) Aspectos teóricos - $\mathrm{O}$ mecanismo discursivo da "escrita"}

É consenso que o papel do livro didático, em seu caráter ideológico dominante, atua na limitação de sua aplicação na prática pedagógica; entretanto, resta interpretar os modos de funcionamento daquilo que lhe é mais caro: o ensino da escrita, e mais aprofundadamente, que uso o livro didático faz da escrita a tentar descrevê-la e apresentá-la como uma tecnologia iluminista do "savoir faire", ou pragmatista do "know how" (FARIA, 1985; ASSOLINI, 1999; CORACINI, 1999; PFEIFFER, 1995).

Deste modo, investigar os prefácios torna-se peça-chave porque se trata de lugares da enunciação em que se propõe antecipar possíveis usos da escrita. Em termos discursivos, trata-se de uma tentativa de controle da interpretação pela via das formações imaginárias.

Pêcheux (1990a) nos fornece dois pontos de apoio para entendermos de que trata a dimensão da formação imaginária no plano da enunciação e do jogo de sentidos entre os enunciados. O primeiro, segundo o autor, vem 
da Psiquiatria clássica e se refere à imagem que o paciente faz de si mesmo, na expressão do autor $\mathrm{Ib}(\mathrm{B})$. O segundo, vindo da relação pedagógica "a representação que os alunos fazem daquilo que o professor lhes designa é que domina o discurso, ou seja, Ib (Ia R)), em sua relação com $\operatorname{Ia}(\mathrm{R})$ ) (PÊCHEUX, 1990a, p. 86)".

Em outras palavras, perguntamos: qual a imagem que este portador de texto (o livro didático) possibilita acerca de possíveis usos da escrita? Quais usos são esperados a partir da concepção de escrita marcada em seus prefácios? De que maneira o prefácio, já pré articula um fazer interpretativo, a que a posição discursiva do aluno deverá se submeter? De que lugar, alhures, tais concepções de escrita enunciam: seja no saber cotidiano, seja no discurso científico da e sobre a escrita?

Torna-se crucial nesta proposta de análise tentar delinear como os mecanismos discursivos de uma determinada materialidade têm por base suas condições de produção. Em suma, tal como aparece na proposta pecheutiana de análise (PECHEUX, 1988), quais localidades do interdiscurso a que recorrem para legitimar sentidos sobre os quais se legitima como recurso de linguagem de circulação social mais amplo. Neste caso, o que permite fazer circular o livro didático? Quais dizeres legitimam sua consolidação, como instrumento supostamente necessário para determinada prática social?

Podemos inicialmente considerar que o livro didático funciona como um "sub-instrumento" do aparelho ideológico do Estado, na linha do que propõe Althusser (apud FARIA, 1985; SOUZA, 1999a).

Somado a isto, pode-se considerar também o funcionamento do discurso pedagógico escolar (DPE), que é mais evidente na escolarização (ainda que não se restrinja a ela) e que, segundo Assolini (1999), impede a polissemia dos discursos e a autoria.

Isto porque a hipertrofia da paráfrase destitui o tecido da linguagem de suas nuances pela legitimação dada pela escolarização à escrita. Tal 
como afirma Pfeiffer (2005), essas nuances são retiradas da constituição processual da linguagem para configurarem produtos unidos - como a escrita escolar, por exemplo - por meio dos quais, é possível fornecer ao sujeito a ilusão de que é um homem discernível, retirado do anonimato cotidiano, e, contraditoriamente, produtor de somente mais um "produto" escolar.

Essa análise se fundamenta nas proposições de Courtine \& Haroche (1988), que mostram que no jogo entre essência e aparência, a imagem predominante não deve ser qualquer uma, mas lapidada, por exemplo, pelas figuras de poder. É o imaginário atravessado pelo político, lugar dos olhares voltados para a dominação, onde se organizam resistências no jogo imaginário das representações.

A repercussão disso no cotidiano escolar pode ser a da utilização do livro didático como um ponto de (não) coincidência entre a dispersão das interpretações possíveis a um fato, fenômeno, opinião, sugestão, $\mathrm{e}$ a legitimação dada pelo próprio espaço da escolarização aos sentidos disputados nas diversas atividades discursivas.

O imaginário, entendido também pela dimensão de uma imagem possível em meio às imagens estabelecidas através do jogo das dominações políticas, serve para relativizar o real das contradições histốricas e o jogo das aparências simbólicas, mas dessa maneira, aparece como lugar de evidência de imagens gerais (“didáticas") impostas como dominantes aos gestos interpretativos particulares.

Neste mecanismo discursivo, o discurso científico encontra espaço pelo uso que faz da relação entre geral e particular, também atravessado por relações de força. A noção de imaginário e, assim, desse tipo de uso da relação entre geral e particular, tal como debatida por estes autores, realiza uma interface com o atributo de dominância da escrita, tal como definida no discurso científico (PEREIRA, 2005). 
No discurso científico, são diversas as teorias acerca do oral e da escrita. É clássica e referência obrigatória a divisão feita por Street (1989) entre "modelo autônomo" e "ideológico". No modelo autônomo, a escrita é considerada um produto acabado em si mesmo, ligada ao progresso, à civilização e à mobilidade social; diferentemente do modelo ideológico, no qual as práticas de escrita são consideradas em seu caráter sócio-histórico e pela determinação cultural.

O mecanismo discursivo de predomínio do modelo autônomo pode começar a ser analisado, conforme Pereira (2005), a partir do que aponta Haroche (1992) acerca do sujeito jurídico. Para Haroche (1992), a passagem da Psicologia pré-científica para a Psicologia científica se deu sob controle do Estado, da Filosofia, da religião e sob a matematização do comportamento. Esta passagem se liga ao caminho da transição do controle da interpretação dos textos, do religioso para o Estado, que assim foi formulada para eliminar ao máximo a ambiguidade. A autora explica como ocorre esta transição. Assim, a tentativa de desambiguização do texto, desde o controle religioso da interpretação foi fortalecida através da promulgação do Edito de Villers Cotterets, na França de 1539 (HAROCHE, 1992).

Com o Edito, explica a autora, o discurso religioso passa a ser tomado pelo discurso jurídico. Para ela, como o religioso não chega mais a cercar o social, e não dá mais conta de controlar a ambiguidade e a vazão de sentidos nos textos e no dogma, o Direito toma seu lugar por formas de um assujeitamento alocado no interior do indivíduo e indispensável a uma economia nascente e livre. Assim, uma partilha igualitária do conhecimento se constrói pela ilusão de liberdade no uso da linguagem.

Esta determinação do sujeito exprime sua relação com um suposto objeto de conhecimento.

É isto que se pretende mostrar, a respeito da maneira como esta determinação se entrelaça com as definições de "escrita", firmadas no 
discurso científico e pasteurizadas nos prefácios de livros didáticos do português brasileiro.

Este efeito de completude da escrita tem a ver com a ilusão tida pelo indivíduo de controlar a linguagem como se esta fosse um objeto acabado em si mesmo. Assim, o sujeito determinado pela interpretação - a qual não controla totalmente nem livremente - precisa da ilusão de ser livre, para interpretar. Esta ilusão, além de atravessada pelo jurídico, é marcada, no discurso científico, pela noção de indivíduo contraposta à noção de sujeito, tal como argumenta Henry (1992).

Assim, se a responsabilidade do sujeito está engajada no seu discurso, como diz Haroche (1992), èle é tratado para acesssar, igualitariamente, um objeto de conhecimento que, julgado pertinente, cumulativo e controlável, estaria ao alcance do seu próprio "julgamento". Esta atribuição interna de liberdade se solidifica com o papel da Psićologia de fortalecer a responsabilidade do Direito atribuída ao indivíduo.

A este respeito Haroche (2005) ainda aponta que a deferência, a condescendência e o acatamento do vassalo aos ditames do soberano sé enquadram de maneira contrastante em relação à preconização de conduta vista atuais democracias.

Citando Haroche (2005, p.133):

Ora, a deferência - que pode depender da amabilidade, da urbanidade, do prazer das maneiras suaves e agradáveis, ou participar de um mecanismo sociológico comporta uma parte intrínseca e irredutível de atenção (autêntica ou aparente), que pode ser de difícil aplicação nas democracias. (...) No Antigo Regime, a atenção era concedida em função das condições e das hierarquias; e a maioria das pessoas, de fato, não recebia nenhuma atenção. Na democracia, a atenção deveria ser igualmente distribuída.

Haroche (2005) ainda cita Shils (apud HAROCHE, 2005), que investiga um desprendimento da deferência explícita nas sociedades 
contemporâneas, sinalizando o desaparecimento dos rituais, mas nem por isso, e por conta do ideal de liberdade, o desaparecimento da deferência.

Contudo, pode-se questionar se estes gestos de deferência caíram em desuso por conta do caráter automático dos rituais modernos, que, teriam se traduzido em tecnologias as mais diversas, dentre as quais, pode-se incluir o livro didático.

A hipertrofia dessas tecnologias, além de se ancorarem na determinação jurídica acima apresentada, vão ao encontro do processo de gramatização se liga à solidificação dos estados das línguas nacionais. Tal como formalizado por Auroux (1992), pelo processo de gramatização, devese entender a condução à descrição e à instrumentação de uma língua "na base de duas tecnologias, que são ainda os pilares de nosso saber metalinguístico: a gramática e o dicionário" (AUROUX, 1992, p.65).

$\mathrm{O}$ autor mostra de que maneira o aparecimento de instrumentos linguísticos mudou as relações sociais. $\mathrm{O}$ conhecimento destes instrumentos linguísticos pelos ocidentais deu acesso a saberes de outras civilizações, através de uma gramática vinda do interesse cultural e político de conhecer do colonizador. É preciso, porém, ponderar que a criação desses instrumentos dá uma falsa impressão de homogeneidade dos saberes, que, na verdade, são construídos historicamente (AUROUX, 1992).

No discurso científico, o efeito de sentido do significante "escrita" tal como caracterizado pelo modelo autônomo é dominante por conta do jogo entre esses dois lugares do imaginário que mencionamos acima. Esses lugares do imaginário implicam-se através da normatização do código imposto pela gramática, a qual vem do controle da interpretação tal como passa a ser exercida pelo jurídico, e que resulta na noção mentalista do indivíduo, que controla, através da escrita, a interpretação (PEREIRA, 2005).

Tais lugares do imaginário, que no nosso entender, são privilegiados para compreender tal efeito de dominância da escrita, se alimentam ainda, 
daquilo que Pêcheux (1997b) denominou artifício da "ciência régia", ou seja, a tentativa da escrita, no discurso científico, fechar-se em si mesma, tal como rege a discursividade do objeto científico pela tentativa de negar o ato interpretativo que a constitui.

Tal estratégia é assim alimentada pela imposição de um sentido único alimentado por instrumentos linguísticos, aliados da dicionarização da língua, como o livro didático e a posição materializada na figura do professor, apresentado como figura detentora de saber único (ASSOLINI, 1999; PACÍFICO, 2003; PFEIFFER, 1995; SOUZA, 1999b).

Do ponto de vista teórico, entendemos que sob o imperativo do sujeito jurídico e a necessidade de atender ao apelo da ideologia, materialliza uma posição-sujeito, cooptada ideologicamente pelos artefatos da gramatização, invariavelmente o Discurso Pedagógico Escolar (D.P.E.) e o livro didático; deste mosaico discursivo, apresenta-se um subprođuto, o prefácio do livro didático.

\section{II) Questões metodológicas}

A investigação de um "dado marginal" filia-se ao paradigma indiciário, em que os "dados" são tomados num continuum, que vai, no caso: de sêu lugar de marginalidade, para passar a serem vistos pelo viés dos giros interpretativos que promovem a uma análise, cujo compromisso é redefinir questões teóricas, pois é imprecisa a relação entre pesquisador e objeto, bem como a relação entre sujeito e linguagem e entre "dado" e interpretação (GINZBURG, 1989; TFOUNI, 1992).

Neste paradigma, o "dado" nunca é diretamente acessível, nem tampouco segue a lógica clássica da delimitação de hipóteses baseadas em controles de variáveis, para a posterior, verificação ou refutação. $\mathrm{Na}$ contrapartida, trata-se de um modelo interpretativo que prezou pelo "sacrifício" de um método consistente com resultados pouco relevantes, 
para apostar na relevância da singularidade e do desbravamento de caminhos desconhecidos, à custa de um método aparentemente frouxo, porém que mergulha na complexidade do objeto investigado (GINZBURG, 1989).

Concorde o paradigma indiciário de análise, a interpretação dos indícios remonta àquilo que está anteposto, e que também mantém um efeito a posteriori em termos das reconfigurações.

Numa perspectiva discursiva inserida neste paradigma, mostramos como os sítios de sentido instalados nestes prefácios escamoteiam interdições à interpretação, e, assim, de assunção da singularidade do sujeito, em textos de universitários, uma vez que alimentam efeitos de préconstruído, na medida em que "criam” imaginariamente concepções sobre a escrita.

\section{II.1) Formação e análise do corpus}

O estranhamento dos efeitos de sentidos mobilizados na materialidade discursiva dos prefácios ancora-se em dispositivos anteriores de análise. Primeiramente, é preciso apresentar de que estranhamentó se trata, para em seguida, apresentar qual lugar da memória discursiva permitiu redimensionar nossa questão inicial, qual seja: de que formas prefácios de livros didáticos realimentam, e legitimam sentidos dominantes sobre a escrita, que, por conta disso, restringem o campo de possibilidades que o sujeito poderá vir a ocupar, ao tentar dela se apropriar, do lugar de intérprete do arquivo.

Do ponto de vista da formação e análise do corpus, o contato com a materialidade discursiva encaminha ecos de uma lacuna da memória discursiva a qual o analista discursivo já acessa em parte, para, em seguida, tentar significar aquilo que lhe pareceu estranho, ao mesmo tempo em que, muito familiar. 
Disso, decorrem os gestos de análise, que tal como aponta Orlandi (1996), seguem o caminho da organização de unidades de sentido, que, sistematizadas via repetição dos enunciados, principalmente, dão conta de pôr a análise num movimento retroativo de volta às questões iniciais.

Trata-se, portanto, logo de início, de considerar que o "dado", como aponta Tfouni (1992), deve ser encarado como parte coincidente, ao mesmo tempo em que não coincidente, com uma das pistas levantadas inicialmente pelo analista.

De modo geral, chamou-nos a atenção fato de que o dispositivo de direcionamento explícito do prefácio é o de tentar antepor sentidos, em relação àqueles que possivelmente poderão sèr postos em jogo pelo sujelitoleitor. Desta maneira, o prefácio tenta preparar o leitor para o que encontrará adiante, ao mesmo tempo em que já neste gesto cristaliza sentidos, que, tais como significantes fundantes, funda sentidos e os organiza segundo o princípio de que a interpretação já deve por retroação à legitimação dos sentidos ali postos.

Isto vai ao encontro do que Pêcheux (1990b) coloca acerca do papel das formações imaginárias, como referentes ancorados em sentidòs do interdiscurso, em que sua movimentação dependerá da maneira pela qual a ideologia interpela as posições-sujeito.

Pêcheux (1988) explica que o interdiscurso é tecido segundo uma complexa rede de formações ideológicas, e discursivas, que se interconectam, ao mesmo tempo em que se dissipam por conta do processo de evidência elementar de que somos sujeitos (à estrutura mais ampla da linguagem), por meio de que os processos sócio-históricos por trás de qualquer enunciado se apresentam apagados destes rastros que os constitui rumo às evidências de adequação semântica que os sustenta.

A reboque disto está a sistematização de qualquer mecanismo das “coisas a saber" na forma de arquivos, que, podendo ser entendidos como o campo de conhecimentos compartilhados ou interditados sócio- 
historicamente dão conta de sustentar diferentes domínios da memória interdiscursiva. As diversas maneiras pelas quais as posições sujeito são construídas, então, dependem de como as formações imaginárias se ancorarão nestes lugares simbólicos do sentido, ao mesmo tempo em que lugares decorrentes de efeitos imaginários. Assim, as formações imaginárias também contribuem para a sustentação e legitimação de algumas evidências ideológicas e o recalque de tantas.

Elas podem ser mais direcionadas e cristalizadoras de um rumo do sentido, a depender do campo de memória em que se filiam, bem como a depender do recurso material à sua disposição, e com este último do tipo de referentes linguísticos por meio dos os sentidos estarão em função de Jum lugar do interdiscurso e não de outros. No caso apresentado, inicialmente queremos mostrar como funciona o nicho da memória discursiva, que resguarda sentidos sobre a "escrita-objeto de conhecimento", e não para sua problematização como constituinte da constituição do sujeito como intérprete. Qual é, portanto, o papel que desempenha o livro didático no controle do acesso ao arquivo?

Assolini (1999) mostra que o livro didático se ancorà no funcionamento do discurso pedagógico, para evidenciar sentidos, em função de uma interpelação do lugar de intérprete do sujeito traduzida na transparência dos atos de linguagem veiculados por recursos da gramatização (AUROUX, 1992), como o livro didático.

A partir da consideração desses determinantes, os prefácios já antecipam a seus interlocutores, seja alfabetizandos ou educadores que deste instrumento farão uso, sentidos sobre a escrita, que certamente controlarão seu uso cotidiano. Mas de que maneira articulam tal antecipação? Em que medida ela se sustenta e dialoga com outros sentidos sobre a escrita? Quais as possibilidades destas antecipações legitimarem uma divisão do trabalho ideológico - já em funcionamento pelo discurso pedagógico - de leitura do 
arquivo, impedindo o intercâmbio destas interpretações, e, com isto, a circulação dos saberes?

Primeiramente, por conta da repetição, que subjaz às práticas mecânicas de leitura e escrita. É o que vemos na primeira sequência discursiva $(\mathrm{SD})$, prefácio subdividido em vários outros prefácios dispostos a cada etapa do livro, através dos tópicos REPRODUÇÃO, PARÁFRASE, CRIAÇÃO.

SD 1 - REPRODUÇÃO. Sabe o que quer dizer produzir? É fazer alguma coisa, uma produção. Sabe o que quer dizer reproduzir? É fazer outra vez, fazer uma reprodução. A reprodução repete a mesma coisa já feita. (...) Nas próximas aulas, você vai começar a fazer reproduções $(\ldots)$ PARÁfRASE. Paráfrase é uma redação que repete outra redação ou texto de modo parecido, semelhante (...) a gente repete, mas muda um pouco. Nas próximas aulas vocề vai aprender a fazer paráfrases (...) CRIAÇÃO. Criar é fazer uma coisa nova, original, diferente. A gente pode até partir đaquilo que já existe como base para criar (...) a criação ou rẹdação criativa é exatamente o contrário da reprodução ou redação reprodutiva. Nas próximas aulas você vai criar muitas redações ou textos (é a mesma coisa)". (retirado de O PRAZER DA REDAÇÃO; MESERANI, 1996).

Tal subdivisão marca explicitamente as etapas de apropriação da escrita. Inicialmente vemos apagar o sentido de criar da reprodução. Por fim, a criação somente poderá ser feita a partir de um texto já trazido, nunca de uma experiência trazida ou outra leitura feita, o que contraria a concessão anteposta em "a gente pode até partir daquilo que já existe". Ora, é possível lidar com a língua se não se está sujeito a ela, e no campo de possíveis usos, a partir do que pré-existe ao sujeito?

Este "totem" da educação formal, o livro didático, que rege o feitiço da escrita, preza que basta usá-lo de forma "correta" que o manuseio da escrita e da interpretação estarão condizentes com um "ideal de escrita". É sabido que a repetição faz parte da interpretação, mas que sobre o mesmo incide o outro, ao qual se constrói a interlocução. 
Mas como legitimar uma lei para os saberes por meio de um totem que massifica a dispersão própria da horda a que se propõe regular? Ou seja, é próprio da lei articular saberes que e de alguma maneira ameaçam a ordem. Assim, como o faz o livro didático se antes mesmo de se propor a regular saberes, já tenta apagar sua dispersão.

A respeito do funcionamento discursivo do livro didático, Grigoletto (1999) analisa as seções destinadas à leitura e produção de textos em livros de ensino de Língua Portuguesa e constata que existem concepções predominantes de leitura, que fundamentam um "como" do poder ligado à leitura e à completude do dizer. Neste jogo, professor e aluno são "usuários" da mesma ferramenta, em seus aspectos normativos, repetitivos e de apresentação. Toda esta engrenagem justifica o fato de o livro do proféssor trazer prefácios curtos, tais como os prefácios vistos aqui, que, embora recortados para tratar de algumas sequências discursivas, preservaram grande parte do tamanho original.

Neste ponto, também vale resgatar Souza (1999b) que analisa as determinações discursivas da escrita do "bom" aluno destinada ao "padrão do professor". Somam-se a isto, os efeitos de acuidade linguística que sustentam enunciados "clichês" em que não se vê disputa de sentidos, por conta da_imposição desta Formação Discursiva que idealiza "uma" escrita para todos, ancorada no "fantasma da criatividade", concebida como algo libertador, mas que restringe possibilidades de interpretação.

Esta restrição aparece marcada pela preconização da "CRIAÇÃO", que, de modo legislador sobre a linguagem, antecipa ao aluno a possibilidade de escrever "texto" ou "redação", com a ressalva de que se trata da mesma coisa. Vemos que o caráter de disputa dos sentidos, de tratamento do imprevisto na linguagem, e da construção ligados ao uso de "texto" (tecido, tessitura) está alienado ao uso de "redação", cujo sentido mobilizado é de um produto ou objeto pronto e acabado. 
Em outro caso, vemos formulações que procuram legitimar o poder da escrita por meio de sentidos tácitos, tanto na forma quanto no conteúdo do substrato escrito, como vemos no:

SD 2 - "você já alcançou duas conquistas muito importantes em sua vida: o momento em que descobriu alguns sons e pronunciou a primeira palavra, tornando-se um falante, e o momento em que você descobriu o sentido de algumas letras e leu a primeira palavra, tornando-se um leitor (...) os livros desta coleção foram criados para que você continue realizando outras importantes conquistas pessoais por meio da leitura e da escrita" (retirado de L.E.R.: LEITURA, ESCRITA E REFLEXÃO; LEITE, 1999).

$\mathrm{O}$ avanço de linguagem a ser conquistado por meio da escrita sugere que os sentidos já estão latentes serem detectados. Isso vai ao encontro do nome do livro - L.E.R.: Leitura, escrita e reflexão - que sinaliza pela topicalização tal movimento. Ou seja, retroagindo com a sequência anterior, acredita-se que é por meio da repetição que se atinge tal patamar tácito na linguagem. Interessante notar que o nome é marcado pela sigla L.E.R.

Esta sigla é velha conhecida dos bordões da medicina do trabalho por se referir à "Lesão por Esforços Repetitivos". Não se trata de forçar umá aproximação afirmar que o uso do livro didático se faz pela repetição mecânica das atividades. No caminho desta articulação outrơ aspecto notável neste caso é o uso da expressão "descoberta do sentído", que impõe uma correspondência direta entre palavra, mundo e linguagem, tal como aparece na sequência anterior e que também pode ser vista em:

SD 3 - "André, conte-me uma coisa. Quando você quer escrever uma história, você escreve direitinho a história que estava em sua cabeça ou você acaba escrevendo outra história? Ele me respondeu: "Eu escrevo outra história, Carmen, porque a que eu imaginei é muito agitada, cheia de ruídos, luzes, cores, tudo acontecendo ao mesmo tempo... e eu não sei como escrever essas coisas. Por isso eu escrevo outra história, a que eu dou conta de escrever. Jamais esqueci aquela conversa com o André. Desde aquele dia tenho procurado descobrir um modo de ajudar as crianças a descobrirem como traduzir luz, cor, som, movimento e muita emoção por escrito. (...) fazendo da escrita uma ponte que traga o mundo para dentro de você e lhe permita traduzir para os outros tudo aquilo 
que pensa, que sabe, que sonha e que sente" (retirado de PORTUGUÊS: UMA PRÁTICA DE LEITURA, ANÁLISE LINGUÍSTICA, PRODUÇÃO DE TEXTO; GUEDES, 1990).

Nesta sequência, as autoras se referem à conversa que tiveram com o aluno "André" o qual relatara que quando ia escrever uma história acabava por escrever o que ele já considerava outra história, mão mais a inicial, pois a primeira é muito cheia de ruídos, e ele escreve a que dá conta de escrever.

Vemos que a "missão" da escrita aqui evangelizada pelo livro didático é a de tirar a criança da admissão de suas limitações para tornar-se um recurso preciso, onipotente, que apagará todas as imperfeições, imprevistos presentes no ato de contar uma história. Os "ruídos" da linguagem serão limpos pelo livro e pela escrita. Trata-se de projeto civilizatório apregoado pela escrita, e repaginado pela versão moderna da liberdade da interpretação. Afinal, trata-se da ajuda fornecida por um modo - qualquer? Para qualquer um? Ou um único, que não diz qual é?

Há neste ponto, na esteira do que coloca Coracini (1999), ửa convergência do instrumento didático baseado numa concepção pragmática de língua, certamente correlata da fundamentação cognitivista do sujeito, à qual também se atribui ao livro didático, como aponta Souza (1999b) ume elo fortalecedor importante do discurso da competência.

Assim, a atribuição do estatuto dado ao livro didático como um recurso que ajuda na descoberta na "tradução de luz, cor, som, movimento e muita emoção por escrito" reflete outro patamar do sentido dominante sobre o livro didático como um lugar de início do caminho para a correspondência direta entre palavra-mundo, por meio da transparência entre mundo interno e mundo externo. Ou seja, é o livro didático que vai por na linha por meio da tradução escrita de "luz, cor e som", a dispersão inicial entre "ruídos, luzes, cores".

Retomando a desconfiança dos gregos analisada por Thomas (2005), podemos considerar que esses prefácios acenam para artifícios de retórica 
cindidos do jogo político da linguagem; isto porque a cisão na leitura do arquivo (PÊCHEUX, 1997) lhes possibilita um lugar aparentemente "deslocado" em relação ao restante do que é dito e dos usos acerca da escrita. Assim, de artifício de retórica que consegue ficar posto de lado, temos neles lugares centralizadores de formações imaginárias, que faz uso da categoria genérica "você", que retroage com "André", mas sinaliza um "ponto de fuga" para qualquer um que utilizar o livro didático.

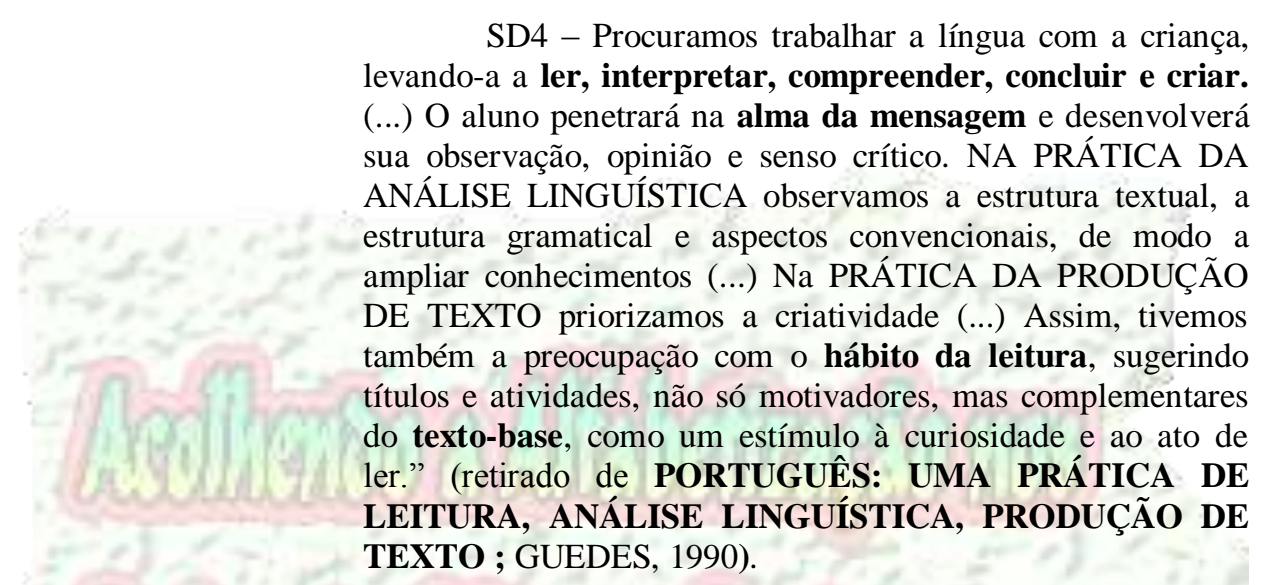

Diante desta sequência, podemos perguntar: Qual tipo de interpretação está demandando do leitor com os negritos? Se a curiosidảde é posta adiante, ou seja, como algo que virá depois do conhecimentó da eserita, apaga-a como um recurso já trazido pelo leitor, por meio de suas leituras prévias. Este ponto de apagamento do processo de intermediação simbólica da e pela linguagem contradiz a priorização da criatividade apontada. Além disso, vale indagar: ler é diferente de interpretar, de tal modo que o livro deva se ocupar somente da leitura?

Neste ponto, vale lembrar Orlandi (2001) para quem a leitura é efeito de trabalho sobre o simbólico que requer considerar as lacunas deste e o modo como estas lacunas promovem possibilidades de outras leituras que tem seus efeitos limitados pelos mecanismos ideológicos. Dentro disso, inserem-se os mecanismos de cisão entre o "científico" e o "literário" na 
leitura do arquivo, que, conforme Pêcheux (1997) contribui com o monopólio dos discursos autoritários e pouco afeitos aos intercâmbios simbólicos.

É ainda este mecanismo de imposição de uma formação discursiva insidiosa o que vemos em:

SD 5 - "Este material foi preparado visando a auxiliar seu trabalho de desenvolvimento da expressão escrita dos alunos. As atividades estão graduadas obedecendo à seguinte sequência: - desinibição, estímulo e ampliação do vocabulário, - com atividades de associações livres e fluência verbal; formação de frases e períodos; - redação propriamente dita. Cada trabalho deve ser primeiro motivado oralmente. É imprescindível que o aluno esteja interessado em realizar a atividade." (retirado de VAMOS ESCREVER? ATIVIDADES DE REDAÇÃO; MENEZES, 1992).

Acima, indicam-se dois elementos veiculadores da formação discursiva dominante acerca do livro didático; primeiramente pela caracterização de melhoria da "expressão escrita", como se esta brotasse de dentro para fora do sujeito, como algo interno aos processos cognitivos; em seguida, aparece o fator "motivado oralmente", como se houvesse umá gradação, do oral à escrita, a ser aprimorada pelo livro.

Fazendo um retrospecto dos recortes analisados, chama a atenção o fato de todos os prefácios se dirigirem somente às crianças, eliminando do debate aquele que de alguma maneira também é co-participante das práticas de leitura e escrita, o professor.

A propósito desta antecipação da curiosidade, é importante salientar o efeito percebido nos prefácios analisados. Trata-se do apagamento do processo pelo qual se fez o livro. Não é dito pensando em quem nem como vai usar. Afinal, o livro didático é o que é sem memória e sem explicação.

Antecipa-se um suposto grau maior de dificuldade com escrita, excluindo todas as nuances de dificuldade presente a depender do contexto tanto com a forma oral quanto com a escrita. 
De modo geral, nos recortes acima, trata-se de concepções ahistóricas da escrita (TFOUNI, 2004). Elas fazem uso do processo de gramatização apontado por Auroux (1992) de modo a favorecer o instrumento linguístico como produto fechado em si mesmo, acabado e circunstanciado. Soma-se a isto, o fato de não serem levados em consideração diversos usos, transformações históricas desse processo. Como aparece na sequência, ao contrário, parte-se do pressuposto que a criança é deficiente e precária no uso da linguagem e a escrita, por meio do livro, que, é claro, vai salvá-la.

Isto demonstra a incidência do discurso jurídico e o funcionamento do processo de reificação da escrita (PEREIRA, 2005). A direção pasşo a passo - "reprodução, paráfrase e criação" na SD1 ou "desinibição, estímulo e ampliação do vocabulário" na SD5 - se firma num imaginário alimentado pela ciência acerca do que é a linearidade da escrita. Por conta disso temos posições sociais já marcadas que aqueles que se apropriam do suporte gráfico da escrita ocupam.

\section{Considerações finais}

A análise aponta a mobilização de um lugar dâ memória (PÊCHEUX, 1997) que reforȩa a interpelação do sujeito livre para a interpretação e reforça o psicologismo traduzido na caracterização das correspondências diretas entre pensamento e linguagem e entre desenvolvimento cronológico e aprimoramento de habilidades para leitura e escrita; ilusão esta ainda sustentada pela crença no aspecto pré-elaborado por parte do alfabetizando, pelo uso da escrita.

Vemos o predomínio da apropriação individual da escrita, pela simbolização de estágios latentes, tal como já criticado por Tfouni (2004), quando esta autora apresenta a contradição entre concepções a-históricas e históricas de letramento. 
Indiretamente nos prefácios de livros didáticos analisados veicula-se uma concepção de simbolização da escrita, que vai do pensamento à linguagem, dos níveis pré-linguísticos à sua elaboração metacognitiva, que contribui, por exemplo, para a interdição do discurso narrativo na escolarização (ASSOLINI, 1999; PACÍFICO, 2003; PEREIRA, 2005), que permite, por exemplo, lidar com a incompletude da estrutura simbólica da língua para lidar com a linguagem em processo de acontecimento.

Para ratificar estes autores, Pereira (2005) mostra que existe um processo de reificação da escrita sustentado pelos determinantes discursivos acima apresentados, que, por sua vez, consolidam posições-intérpretes do sujeito do discurso marcadas pelo crivo dos éfeitos de verdade articuladòs à transparência da língua nas definições "sobre" a escrita "na" escrita científica.

Isto é feito pelo uso de instrumentos como dicionário, gramatização (AUROUX, 1992) e pelo efeito de domínio do paradigma científico galileano, ainda articulado ao funcionamento deste disfarçado em mecanismos de controle da interpretação no discurso (PEREIRA, 2005), tais como os prefácios de livros didáticos analisados neste artigo.

De modo mais amplo, este artigo articula-se às reflexões-sobre práticas de leitura e escrita que extrapolam seus usos escolares, porque comprometidas com a complexidade enunciativa e discursiva das práticas letradas nos estudos sobre letramento.

\section{REFERÊNCIAS BIBLIOGRÁFICAS}

ASSOLINI, F.E.P. Pedagogia da leitura parafrástica. 1999. $95 \mathrm{f}$. Dissertação (Mestrado em Psicologia). Faculdade de Filosofia, Ciências e Letras de Ribeirão Preto da Universidade de São Paulo. Texto não publicado Tese de Doutorado. FFCLRP-USP. Ribeirão Preto-SP. 1999.

AUROUX, S. A revolução tecnológica da gramatização. Campinas/SP: Ed. da UNICAMP, 1992. 
CÓCCIO, M. F.; HALlER, M. A. ALP novo: análise, linguagem e pensamento. SP: FTD. 1999.

CORACINI, M. J. R. F. O livro didático nos discursos da linguística aplicada e da sala de aula. IN.: CORACINI, M. J. (org.). Interpretação, autoria e legitimação do livro didático: língua materna e língua estrangeira. Campinas/SP: Pontes. 1999. 17-26.

COURTINE, J. J.; HAROCHE, C.. O Homem perscrutado: semiologia e antropologia política da expressão e da fisionomia do século XVII ao século XIX. Tradução L. R. Romano. In: LANE, S. M. T.. Sujeito e Texto. EDU. São Paulo/SP: 1988. 37-60.

FARIA, A. Ideologia no livro didático. SP: Cortez. 1985.

GINZBURG, C. Mitos, emblemas e sinais: morfologia e História. São Paulo/SP: Cia das Letras. 1989.

GUEDES, M. Português: uma prática de leitura, análise linguística, produção de texto, 2a . Série. SP: Editora do Brasil, 1990.

GRIGOLETTO, M. Leitura e funcionamento discursivo do livro didático. IN.: CORACINI, M. J.. (org.). Interpretação, autoria e legitimação do livro didático: língua materna e língua estrangeira. Campinas/SP: Pontes. 1999. 67-77.

HAROCHE, C. Fazer dizer, querer dizer. Editora Hucitec. São Paulo/SP: 1992.

O-comportamento de deferência: do cortesão ă personalidade democrática. Tradução de J. A. S. IN: revista História: questões \& debates. Curitiba, n.42, p.115-139, 2005, ed. da UFPR.

HENRY, P. A. Ferramenta imperfeita: língua, História e discurso. Campinas/SP: Ed. da UNICAMP. 1992.

LEITE, M.; BASSI, C. M. L.E.R.: Leitura, escrita e reflexão. São Paulo: FTD. 1999.

LIPPI, V. M. M. De palavra em palavra. SP: FTD. 1991.

MENEZES, C. Z. Vamos escrever? : atividades de redação. SP: FTD. 1992. 
MESERANI, S. O prazer da redação. SP: Ática. 1996.

ORLANDI, E. P. Discurso: fato, dado, exterioridade. In.: CASTRO, M.F.P. (org.). $\mathrm{O}$ método e o dado no estudo da linguagem. Campinas/SP. Ed. da UNICAMP, 1996, p. 209-219.

Discurso e texto. In.: ORLANDI, E.P. Interpretação: autoria, leitura e efeitos do trabalho simbólico. Petrópolis/RJ: Vozes. 2001. 52-62.

PACÍFICO, S. M. R. Argumentação e autoria: o silenciamento do dizer. 2002. 196f. Tese (Doutorado em Psicologia). Faculdade de Filosofia, Ciências e Letras de Ribeirão Preto da Universidade de São Paulo. Texto não publicado. 2002.

PÊCHEUX, M. Análise Automática do Discurso (AAD-69). IN.: F. GADET \& T. HAK. Por uma análise automática do discurso : uma introdução à obra de Michel Pêcheux. Campinas/SP: UNICAMP. 1990a. 61-105.

Delimitações, inversões, deslocamentos. In.: Cadernos

de Estudos Linguísticos, Campinas, (19): 7-24, jul/dez, 1990 b.

- Semântica e discurso: uma crítica à afirmação do óbvio. Campinas: Ed. da UNICAMP. 1988.

Ler o arquivo hoje. In.: ORLANDI, E. P. (org.). Gestos de

Leitura: da História no discurso. Campinas/SP. Ed. da UNICAMP. 1997b, p. 55-67.

PEREIRA,- A. C. Letramento, esquecimento e alteridade. o processo de reificação da escrita. 2005. Dissertação de Mestrado, Ribeirão Preto/SP. Faculdade de Filosofia, Ciências e Letras de Ribeirão Preto da Universidade de São Paulo. Texto não publicado.

PFEIFFER, C. C. O saber escolarizado como espaço de institucionalização da língua. In: GUIMARÃES, E.; BRUM-DE-PAULA, M. R. (orgs.). Sentido e memória. Campinas: Pontes. 2005.

SOUZA, D.M. Autoridade, autoria e livro didático. IN.: CORACINI, M.J. (org.). Interpretação, autoria e legitimação do livro didático: língua materna e língua estrangeira. Campinas/SP: Pontes. 1999a. 27-31. 
Ideal de escrita e livro didático. IN.: CORACINI, M.J. (org.). Interpretação, autoria e legitimação do livro didático: língua materna e língua estrangeira. Campinas/SP: Pontes. 1999b. 135-138.

TFOUNI, L. V. O dado como indício e a contextualização do(a) pesquisador(a) nos estudos sobre compreensão da linguagem. Revista D.E.L.T.A, v. 8, n.2, SCT/PR, p. 205-223, 1992.

Letramento e alfabetização. SP: Cortez. 2004.

THOMAS, R.. Letramento e oralidade na Grécia Antiga. [tradução Raul Fiker]. São Paulo/SP: Odysseus editora, 2005.

\section{Autor:}

Prof. Dr. Anderson de Carvalho Pereira

Professor Adjunto - Departamento de Estudos Básicos e Instrumentais

Universidade Estadual do Sudoeste da Bahia

Contato: apereira.uesb@gmail.com.

Texto recebido em março de 2011.

Texto aprovado para publicação em junho de 2011.

\section{Como citar este texto:}

PEREIRA, A. de C. P.. Prefácios de livros didáticos e o imaginário da leitura: do dado marginal à legitimação de um lugar da escrita. Revista Acolhendo a Alfabetização nos Países de Língua Portuguesa, Brasil, São Paulo, volume 1, no. 11, pp. 146 - 148, Set.. 2011. Disponível em: $\langle$ http://www.acoalfaplp.net>. 